\title{
Strongly Pure Fuzzy Ideals And Strongly Pure Fuzzy Submodules
}

Hatam.Y.Khalaf, Shaymaa.A.Alkareem

Department of Mathematics, College of Education, University of Baghdad

Abstract

The main aim of this paper is to extend and study the notion of (ordinary) S-pure ideal( submodule) into S-pure fuzzy ideal (submodule) and S-regular ring (module) into S-regular fuzzy ring (module) This lead us to introduced and study other notions such as S-pure fuzzy ideal (submodule) and S-regular fuzzy ring (module).

\section{Introduction}

Let I fuzzy ideal of a ring $\mathrm{R}$. it is well known that $\mathrm{I}$ is called $\mathrm{S}$-pure fuzzy ideal of $\mathrm{R}$ if for each $r_{\ell} \subseteq \mathrm{I}$, there exists a prime fuzzy singleton $\mathrm{x}_{\mathrm{t}} \subseteq \mathrm{I}$ such that $\mathrm{r}_{\ell}=\mathrm{r}_{\ell} \mathrm{x}_{\mathrm{t}}, \forall \mathrm{t}, \ell \in(0,1]$.

And a fuzzy ring $\mathrm{R}$ is called $\mathrm{S}$-regular fuzzy if and only if for each fuzzy singleton $\mathrm{r}_{\ell}$ of $\mathrm{R}$, there exists a prime fuzzy singleton $x_{t}$ of $R$ such that $r_{\ell}=r_{\ell} x_{t} r_{\ell}, \forall t, \ell \in(0,1]$.

In this paper, we fuzzify these concepts S-pure fuzzy ideal (submodule) and S-regular fuzzy ring (module), moreover we generalize many properties of S-pure fuzzy ideal (submodule) and S-regular fuzzy ring (module).

This paper consists of four part. In part one, various basis properties about strongly pure fuzzy ideals are discussed . part two included strongly regular fuzzy ring and basic properties about this concept. Part three study the strongly pure fuzzy submodules. Part four is definition the strongly regular fuzzy module and study the property of strongly regular fuzzy module.

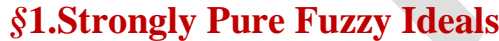

\section{Definition (1.1)}

Let $\mathrm{I}$ be a fuzzy ideal of a ring $\mathrm{R}, \mathrm{I}$ is called pure fuzzy ideal if for each $\mathrm{x}_{\mathrm{t}} \subseteq \mathrm{I}$, there exists $\mathrm{r}_{\ell} \subseteq \mathrm{I}$ such that $\mathrm{x}_{\mathrm{t}}=\mathrm{x}_{\mathrm{t}} \mathrm{r}_{\ell}, \forall \mathrm{t}, \ell \in(0,1]$.

\section{$\underline{\text { Definition (1.2) }}$}

Let $x_{t}: R \rightarrow[0,1]$ such that $x_{t}(p)=\left\{\begin{array}{cc}t & \text { if } x=p \\ 0 & \text { otherwise }\end{array}\right.$ Where $p$ is prime number of $R$. 


\section{$\underline{\text { Definition (1.3) }}$}

Let $\mathrm{K}$ be a fuzzy ideal of a ring $\mathrm{R}, \mathrm{K}$ is called strongly pure fuzzy ideal denoted by S-pure fuzzy ideal if for each $r_{\ell} \subseteq K$, there exists a prime fuzzy singleton $x_{t} \subseteq K$ such that $r_{\ell}=r_{\ell} x_{t}, \forall$ $\mathrm{t}, \ell \in(0,1]$.

\section{Proposition (1.4)}

Let $I$ be a fuzzy ideal of $R$ then $I$ is S-pure if and only if $I_{t}$ is a S-pure ideal of $R, \forall t \in(0,1]$.

Proof:

$(\Longrightarrow)$ Let $r_{\ell}=r_{\ell} x_{t}, \forall \ell, t \in(0,1]$. To show that $r=r x$

$\mathrm{r}_{\ell}=(\mathrm{rx})_{\ell} \quad$ where $\ell=\min \{\ell, \mathrm{t}\}$ by $[1]$

$\mathrm{r}=\mathrm{rx} \quad$ by[4]

Then $I_{t}$ is $S$-pure ideal of $R, \forall t \in(0,1]$.

$$
(\Leftarrow) \text { let } \mathrm{r}=\mathrm{rx} \text { To prove } \mathrm{r}_{\ell}=\mathrm{r}_{\ell} \mathrm{x}_{\mathrm{t}} \forall \ell, \mathrm{t} \in(0,1]
$$

$\mathrm{r}=\mathrm{rx}$ implies $\mathrm{r}_{\ell}=(\mathrm{rx})_{\ell} \quad$ by[4]

$r_{\ell}=r_{\ell} x_{t} \quad$ where $\ell=\min \{\ell, t\}$ by $[1]$

Therefore I is a S-pure fuzzy ideal of $\mathrm{R}$.

\section{$\underline{\text { Definition (1.5) }}$}

An fuzzy singleton $a_{t}$ of $R$ is called fuzzy idempotent if $\left(a_{t}\right)^{2}=a_{t} \forall t \in(0,1]$.

\section{$\underline{\text { Remarks and Examples (1.6) }}$}

1-Let $\mathrm{K}$ be a fuzzy ideal of a ring $\mathrm{R}$, if $\mathrm{K}$ is $\mathrm{S}$-pure fuzzy ideal then $\mathrm{K}$ is pure fuzzy ideal.

Proof: it is clear

The converse not true by

Example: A ring $\mathrm{Z}_{6}$ and $\mathrm{N}=(\overline{3})=\{\overline{0}, \overline{3}\} \quad, \mathrm{K}=(\overline{2})=\{\overline{0}, \overline{2}, \overline{4}\}$

Define $K: \mathrm{Z}_{6} \rightarrow[0,1]$ by $\mathrm{I}(\mathrm{x})=\left\{\begin{array}{cc}\mathrm{t} & \text { if } \mathrm{x} \in \mathrm{N} \\ \mathrm{o} & \text { otherwise }\end{array} \quad \forall \mathrm{t} \in(0,1]\right.$ 
Define $\mathrm{J}: \mathrm{Z}_{6} \rightarrow[0,1]$ by $\mathrm{J}(\mathrm{x})=\left\{\begin{array}{cc}\mathrm{t} & \text { if } \mathrm{x} \in \mathrm{K} \\ \mathrm{o} & \text { otherwise }\end{array} \quad \forall \mathrm{t} \in(0,1]\right.$

It is clear that $\mathrm{K}$ and $\mathrm{J}$ is fuzzy ideal of $\mathrm{Z}_{6}$ and $\mathrm{J}_{\mathrm{t}}=\mathrm{K}, \mathrm{K}_{\mathrm{t}}=\mathrm{N}$

$\mathrm{K}_{\mathrm{t}}$ is $\mathrm{S}$-pure ideal of $\mathrm{Z}_{6}$ by [5]

Thus $\mathrm{K}$ is S-pure fuzzy ideal of a ring $\mathrm{Z}_{6}$ by(Proposition 3.1.4)

But $\mathrm{J}_{\mathrm{t}}$ is not $\mathrm{S}$-pure ideal of a ring $\mathrm{Z}_{6}$ by [5]

Hence $\mathrm{J}$ is not $\mathrm{S}$-pure fuzzy ideal of $\mathrm{Z}_{6}$ by(Proposition 3.1.4)

But $\mathbf{J}$ is pure fuzzy ideal.

2- Let $\mathrm{K}$ be a fuzzy ideal of a ring $\mathrm{R}$. If $\mathrm{K}$ is $\mathrm{S}$-pure fuzzy ideal of $\mathrm{R}$, then $\mathrm{JK}=\mathrm{J} \cap \mathrm{K}$ for each fuzzy ideal $\mathrm{J}$ of $\mathrm{R}$.

3- Let $\mathrm{K}$ be a fuzzy ideal of a ring $\mathrm{R}$. If $\mathrm{K}$ generated by prime idempotent fuzzy singleton, then $\mathrm{K}$ is S-pure fuzzy ideal

Proof:

Let $K=\left(p_{s}\right)$ be a fuzzy ideal generated by prime fuzzy singleton $p_{t}, \forall t \in(0,1]$

Such that $\mathrm{p}_{\mathrm{s}}=\mathrm{p}_{\mathrm{s}}^{2}$. If $\mathrm{x}_{\mathrm{t}} \subseteq \mathrm{K}$ there exists fuzzy singleton $\mathrm{r}_{\ell}$ of $\mathrm{R}$ such that $\mathrm{x}_{\mathrm{t}}=\mathrm{r}_{\ell} \mathrm{p}_{\mathrm{s}}$ implies $\mathrm{x}_{\mathrm{t}}=$ $\mathrm{r}_{\ell} \mathrm{p}_{\mathrm{s}}=\mathrm{r}_{\ell} \mathrm{p}_{\mathrm{s}}^{2}=\mathrm{r}_{\ell} \mathrm{p}_{\mathrm{s}} \mathrm{p}_{\mathrm{s}}=\mathrm{x}_{\mathrm{t}} \mathrm{p}_{\mathrm{s}}$

Therefore $\mathrm{K}$ is S-pure fuzzy ideal of a ring $\mathrm{R}$.

4-Let $\mathrm{K}$ be a fuzzy ideal of a $\operatorname{ring} \mathrm{R}$, if $\mathrm{K}$ is $\mathrm{S}$-pure fuzzy ideal then $\mathrm{K}$ is idempotent .

Proof:

Let $\mathrm{K}$ be a S-pure fuzzy ideal of $\mathrm{R}$. and let $\mathrm{r}_{\ell} \subseteq \mathrm{K}, \forall \ell \in(0,1]$

Then there exists a prime fuzzy $\mathrm{x}_{\mathrm{t}} \subseteq \mathrm{K}$.

Such that $r_{\ell}=r_{\ell} x_{t} \forall \ell, t \in(0,1]$ but $r_{\ell} x_{t} \subseteq K . K$

Hence $\mathrm{r}_{\ell} \subseteq \mathrm{K}^{2}$. Thus $\mathrm{K} \subseteq \mathrm{K}^{2}$ and it is clear that $\mathrm{K}^{2} \subseteq \mathrm{K}$. implies $\mathrm{K}=\mathrm{K}^{2}$.

Therefore $\mathrm{K}$ is idempotent fuzzy ideal of $\mathrm{R}$.

\section{$\underline{\text { Definition (1.7) }}$}

Let $R$ be a fuzzy ring, then there exists $1_{t}$ of $R$ such that $a_{t} \cdot 1_{t}=(a \cdot 1)_{t}=a_{t}$ for all fuzzy singleton $a_{t}$ of $R \cdot a_{t}$ is called unit fuzzy singleton. 


\section{Definition (1.8)}

Let $x_{t}$ be a fuzzy singleton of $R$ is called fuzzy irreducible if $x_{t}=r_{\ell} y_{s}$. where $r_{\ell} \neq 0_{1} \neq y_{s}$ is a fuzzy singleton of $R, \forall \ell, s, t \in(0,1]$ it is non unit fuzzy singleton of $R$ then either $r_{\ell}$ or $y_{s}$ is unity of $R$.

Now, we interdace the concepts of fuzzy factorial ring

\section{$\underline{\text { Definition (1.9) }}$}

let $S$ be a non empty fuzzy subset of $R$, and has no fuzzy singlet unit of integral domain of $\mathrm{R}$, then $\mathrm{R}$ is called fuzzy factorial if every non empty fuzzy singleton of $\mathrm{R}$.written uniquely form $\mathrm{y}_{\mathrm{r}} \mathrm{x}_{\mathrm{t} 1} \ldots \ldots \mathrm{x}_{\mathrm{tk}}$ where $\mathrm{y}_{\mathrm{r}}$ is unit of $\mathrm{R}$ and $\mathrm{x}_{\mathrm{t} 1} \ldots . \mathrm{x}_{\mathrm{tk}} \subseteq \mathrm{S}, \forall \mathrm{r}, \mathrm{t} \in(0,1]$.

\section{$\underline{\text { Lemma (1.10) }}$}

Let $\mathrm{R}$ be a factorial fuzzy ring. Then every irreducible fuzzy singleton $\mathrm{y}_{\mathrm{r}}$ of $\mathrm{R}$ is fuzzy prime every , $x_{t} \subseteq S$ is prime fuzzy singleton and every prime fuzzy singleton of set $S$ is the product of unit of $\mathrm{R}, \forall \mathrm{t} \in(0,1]$.

Proof:

Let $\mathrm{y}_{\mathrm{r}}$ irreducible fuzzy singleton of $\mathrm{R}$

Thus $\mathrm{y}_{\mathrm{r}}$ is non unit and if $\mathrm{a}_{\mathrm{s}} \mathrm{b}_{\mathrm{r}} \subseteq\left(\mathrm{y}_{\mathrm{r}}\right)$

Then $\mathrm{a}_{\mathrm{s}} \mathrm{b}_{\mathrm{r}}=\mathrm{x}_{\mathrm{t}} \mathrm{y}_{\mathrm{r}}$ with $\mathrm{x}_{\mathrm{t}} \subseteq \mathrm{S}$. we write $\mathrm{a}_{\mathrm{s}}, \mathrm{b}_{\mathrm{r}}, \mathrm{x}_{\mathrm{t}}$ as product of irreducible

$a_{\mathrm{s}}=\mathrm{y}_{\mathrm{r} 1} \ldots . \mathrm{y}_{\mathrm{ri}} \quad \mathrm{b}_{\mathrm{r}}=\mathrm{q}_{\mathrm{k} 1} \ldots . . \mathrm{q}_{\mathrm{km}} \quad \mathrm{x}_{\mathrm{t}}=\mathrm{r}_{\ell 1} \ldots . . \mathrm{r}_{\ell \mathrm{n}}, \forall \mathrm{r}, \mathrm{k}, \mathrm{t} \in(0,1]$.

Here, one of those first two product may be empty

$\mathrm{y}_{\mathrm{r} 1} \ldots . \mathrm{y}_{\mathrm{ri}} \mathrm{q}_{\mathrm{k} 1} \ldots . . \mathrm{q}_{\mathrm{km}}=\mathrm{r}_{\ell 1} \ldots . \mathrm{r}_{\ell \mathrm{n}} \mathrm{y}_{\mathrm{r}}$

It is mean that either $\mathrm{a}_{\mathrm{s}} \subseteq\left(\mathrm{y}_{\mathrm{r}}\right)$ or $\mathrm{b}_{\mathrm{r}} \subseteq\left(\mathrm{y}_{\mathrm{r}}\right)$

Thus $\left(\mathrm{y}_{\mathrm{r}}\right)$ is prime fuzzy ideal of $\mathrm{R}$ and it is generated by prime

\section{$\underline{\text { Proposition (1.11) }}$}

Let $\mathrm{K}$ be fuzzy ideal of $\mathrm{R}$. And let $\mathrm{R}$ be a factorial fuzzy ring, such that $\mathrm{y}_{\mathrm{r}} \neq 0_{1}$ non unit fuzzy singleton of $R$ is fuzzy irreducible. Then $K$ is $S$-pure fuzzy ideal $\Leftrightarrow K$ is pure fuzzy ideal.

Proof:

Let $\mathrm{K}$ be a pure fuzzy ideal of $\mathrm{R}$, and let $\mathrm{r}_{\ell} \subseteq \mathrm{K}$, there exists $\mathrm{x}_{\mathrm{t}} \subseteq \mathrm{K}$, such that $\mathrm{r}_{\ell}=\mathrm{r}_{\ell} \mathrm{x}_{\mathrm{t}}$. since $\mathrm{x}_{\mathrm{t}} \subseteq \mathrm{R}$, is irreducible fuzzy singleton of $\mathrm{R}$

Hence $\mathrm{x}_{\mathrm{t}}$ is prime of $\mathrm{K}$ by (lemma3.1.10)

Therefore $\mathrm{K}$ is S-pure fuzzy ideal of $\mathrm{R}$. 
The conversely is clear .

\section{$\underline{\text { Proposition (1.12) }}$}

Let $\mathrm{K}$ and $\mathrm{H}$ are two fuzzy ideal of a ring $\mathrm{R}$, if $\mathrm{K}$ is S-pure fuzzy ideal of $\mathrm{R}$ then $\mathrm{K} \cap \mathrm{H}$ is S-pure fuzzy ideal of R.

Proof: obviously.

\section{$\underline{\text { Proposition (1.13) }}$}

Let $\mathrm{K}$ and $\mathrm{H}$ are two fuzzy ideal of a ring $\mathrm{R}$, such that $\mathrm{K} \subseteq \mathrm{H}$ if $\mathrm{K} \cap \mathrm{H}$ is S-pure fuzzy ideal of $\mathrm{R}$, then $\mathrm{K}$ is $\mathrm{S}$-pure fuzzy ideal of $\mathrm{R}$.

Proof: it is clear

\section{Corollary (1.14)}

Let $\mathrm{K}$ and $\mathrm{H}$ are two S-pure fuzzy ideal of a ring $\mathrm{R}$, then $\mathrm{K} \cap \mathrm{H}$ is $\mathrm{S}$-pure fuzzy ideal of $\mathrm{R}$.

\section{Corollary (1.15)}

Let $\mathrm{K}$ and $\mathrm{H}$ are two fuzzy ideal of a ring $\mathrm{R}$, then $\mathrm{K}$ is $\mathrm{S}$-pure fuzzy ideal of $\mathrm{R} \Leftrightarrow \mathrm{K} \cap \mathrm{H}$ is S-pure fuzzy ideal of $\mathrm{R}$.

\section{Proposition (1.16)}

Let $\mathrm{K}$ and $\mathrm{H}$ are two fuzzy ideal of a ring $\mathrm{R}$, if $\mathrm{K} \oplus \mathrm{H}$ is $\mathrm{S}$-pure fuzzy ideal of $\mathrm{R}$. then either $\mathrm{K}$ or $\mathrm{H}$ is S-pure fuzzy ideal of $\mathrm{R}$.

\section{Proof:}

Let $\mathrm{x}_{\mathrm{t}} \subseteq \mathrm{K}$ and $\mathrm{y}_{\mathrm{t}} \subseteq \mathrm{H}$, implies $\mathrm{x}_{\mathrm{t}}+\mathrm{y}_{\mathrm{t}} \subseteq \mathrm{K} \oplus \mathrm{H}$

Since $K \oplus H$ is $S$-pure fuzzy ideal of $R$. there exists a prime fuzzy $r_{\ell} \subseteq K \oplus H$

Where $\mathrm{r}_{\ell}=\mathrm{r}_{\ell}+0 \subseteq \mathrm{K} \oplus \mathrm{H}$

Such that $\mathrm{x}_{\mathrm{t}}+\mathrm{y}_{\mathrm{t}}=\left(\mathrm{x}_{\mathrm{t}}+\mathrm{y}_{\mathrm{t}}\right) \mathrm{r}_{\ell}=\left(\mathrm{x}_{\mathrm{t}}+\mathrm{y}_{\mathrm{t}}\right)\left(\mathrm{r}_{\ell}+0\right)=\mathrm{x}_{\mathrm{t}} \mathrm{r}_{\ell}+\mathrm{y}_{\mathrm{t}} \mathrm{r}_{\ell} \subseteq \mathrm{K} \oplus \mathrm{H}$

Since $\mathrm{y}_{\mathrm{t}} \mathrm{r}_{\ell} \subseteq \mathrm{K} \cap \mathrm{J}$ and $\mathrm{K} \cap \mathrm{H}=\{0\}$

Hence $\mathrm{y}_{\mathrm{t}} \mathrm{r}_{\ell}=0$. Thus $\mathrm{x}_{\mathrm{t}}=\mathrm{x}_{\mathrm{t}} \mathrm{r}_{\ell} \subseteq \mathrm{K}$.

Therefore $\mathrm{K}$ is S-pure fuzzy ideal of $\mathrm{R}$.

And if $r_{\ell}=0+r_{\ell} \subseteq K \oplus J$. then we can get $H$ is $S$-pure fuzzy ideal of $R$. 


\section{Corollary (1.17)}

Let $\mathrm{K}$ and $\mathrm{H}$ are two fuzzy ideal of $\mathrm{R}$ and let $\mathrm{R}$ be a factorial fuzzy ring, such that $\mathrm{K} \oplus \mathrm{H}$ is S-pure fuzzy ideal of $\mathrm{R}$. then $\mathrm{K}$ and $\mathrm{H}$ are S-pure fuzzy ideal of $\mathrm{R}$.

\section{"Definition (1.18)}

The fuzzy Jacobson radical of a ring R denoted by F-J $(R)$ is the intersection of all fuzzy maximal ideal of R.[3]"

\section{Proposition (1.19)}

Let $\mathrm{K}$ is $\mathrm{S}$-pure fuzzy ideal of $\mathrm{R}$, such that $\mathrm{K} \subseteq \mathrm{F}-\mathrm{J}(\mathrm{R})$, then $\mathrm{K}=\{0\}$

Proof:

Let $r_{\ell} \subseteq K$, since $K$ is S-pure fuzzy ideal of $R$ there exists a prime $x_{t} \subseteq K$, such that $r_{\ell}=r_{\ell} x_{t}$ Implies $r_{\ell}\left(1-x_{t}\right)=0$. And since $\mathrm{K} \subseteq \mathrm{F}-\mathrm{J}(\mathrm{R})$, then $\mathrm{x}_{\mathrm{t}} \subseteq \mathrm{F}-\mathrm{J}(\mathrm{R})$.

Hence $r_{\ell}=0$, so $\mathrm{K}=\{0\}$.

\section{\$2.Strongly Regular Fuzzy Ring}

\section{$\underline{\text { Definition (2.1) }}$}

A fuzzy ring $\mathrm{R}$ is called regular if and only if for each fuzzy singleton $\mathrm{x}_{\mathrm{t}}$ of $\mathrm{R}$, there exists fuzzy singleton $r_{\ell}$ of $R$ such that $x_{t}=x_{t} r_{\ell} x_{t}, \forall t, \ell \in(0,1]$.

\section{$\underline{\text { Definition (2.2) }}$}

Let $\mathrm{R}$ be a fuzzy ring. $\mathrm{R}$ is called strongly regular denoted by S-regular fuzzy if and only if for each fuzzy singleton $r_{\ell}$ of $R$, there exists a prime fuzzy singleton $x_{t}$ of $R$ such that $r_{\ell}=r_{\ell} x_{t} r_{\ell}, \forall$ $\mathrm{t}, \ell \in(0,1]$.

Equivalent a ring R is S-regular fuzzy if for each fuzzy singleton of R is S-regular fuzzy.

\section{Proposition (2.3)}

Let $\mathrm{R}$ be a $\mathrm{S}$-regular fuzzy ring $\Leftrightarrow \mathrm{R}_{\mathrm{t}}$ be $\mathrm{S}$-regular ring, $\forall \mathrm{t} \in(0,1]$.

Proof:

$(\Longrightarrow)$ Let $\mathrm{R}$ be a S-regular fuzzy ring To prove $\mathrm{R}_{\mathrm{t}}$ is $\mathrm{S}$-regular ring $\mathrm{r}_{\ell}=\mathrm{r}_{\ell} \mathrm{x}_{\mathrm{t}} \mathrm{r}_{\ell}, \forall \ell, \mathrm{t} \in(0,1]$.

implies $r_{\ell}=(r x r)_{\ell}$ where $\ell=\min \{\ell, t\}$ by $[1]$

$\mathrm{r}=\mathrm{r} \times \mathrm{r} \quad$ by[4]

Then $\mathrm{R}_{\mathrm{t}}$ is $\mathrm{S}$-regular ring, $\forall \mathrm{t} \in(0,1]$. 
$(\Leftarrow)$ let $\mathrm{R}_{\mathrm{t}}$ be S-regular ring to show that $\mathrm{R}$ is $\mathrm{S}$-regular fuzzy ring

Let $\mathrm{r}=\mathrm{r} \mathrm{x} \mathrm{r}$ To prove $\mathrm{r}_{\ell}=\mathrm{r}_{\ell} \mathrm{x}_{\mathrm{t}} \mathrm{r}_{\ell} \forall \ell, \mathrm{t} \in(0,1]$

$\mathrm{r}=\mathrm{rxr}$ implies $\mathrm{r}_{\ell}=(\mathrm{rxr})_{\ell}$ where $\ell=\min \{\ell, \mathrm{t}\}$ by[4]

$\mathrm{r}_{\ell}=\mathrm{r}_{\ell} \mathrm{x}_{\mathrm{t}} \mathrm{r}_{\ell} \quad$ by[1]

Therefore $\mathrm{R}$ is S-regular fuzzy ring .

\section{Remarks and Examples (2.4)}

1- Let $R: Z_{4} \rightarrow[0,1]$ define by

$\mathrm{R}(\mathrm{r})=\left\{\begin{array}{cc}\mathrm{t} & \text { if } \mathrm{r} \in \mathrm{Z}_{4} \\ \mathrm{o} & \text { otherwise }\end{array} \quad \forall \mathrm{t} \in(0,1]\right.$

It is clear that $\mathrm{R}_{\mathrm{t}}=\mathrm{Z}_{4}$ and $\mathrm{Z}_{4}$ is S-regular ring [5]

Thus $\mathrm{R}$ is S-regular fuzzy ring. by proposition(3.2.3)

By the same mothed we can to show that if $R_{t}=Z_{6}$ is not $S$-regular fuzzy ring and we get $R$ is not S-regular fuzzy ring.

2-Let $\mathrm{R}$ be a fuzzy ring, if $\mathrm{R}$ is $\mathrm{S}$-regular fuzzy, then $\mathrm{R}$ is regular fuzzy ring.

Proof: it is clear

The converse not true for example

Example: Let $\mathrm{R}: \mathrm{Z}_{6} \rightarrow[0,1]$ define by

$\mathrm{R}(\mathrm{r})=\left\{\begin{array}{lr}\mathrm{t} & \text { if } \mathrm{r} \in \mathrm{Z}_{6} \\ \mathrm{o} & \text { otherwise }\end{array} \quad \forall \mathrm{t} \in(0,1]\right.$

It is clear that $\mathrm{R}_{\mathrm{t}}=\mathrm{Z}_{6}$ and $\mathrm{Z}_{6}$ is regular ring, but $\mathrm{Z}_{6}$ is not $\mathrm{S}$-regular ring

Then $\mathrm{R}$ is not S-regular fuzzy ring . by proposition(3.2.3)

3- every fuzzy ideal of $\mathrm{R}$ is irreducible and let $\mathrm{R}$ be a factorial fuzzy ring, then $\mathrm{R}$ is $\mathrm{S}$-regular fuzzy ring $\Leftrightarrow$ fuzzy ideal of $R$ is S-pure fuzzy.

\section{Proposition (2.5)}

Let $R_{1}$ and $R_{2}$ are two fuzzy ring, if $R_{1} \oplus R_{2}$ is S-regular fuzzy ring. Then either $R_{1}$ or $R_{2}$ is $S$ regular fuzzy ring.

Proof:

Let fuzzy singleton $r_{\ell 1}$ of $R_{1}$ and $r_{\ell 2}$ of $R_{2}$

Implies $r_{\ell 1}+r_{\ell 2} \subseteq R_{1} \oplus R_{2}$. Put $x_{t}=r_{\ell 1}+r_{\ell 2}$ 
Since $\mathrm{R}_{1} \oplus \mathrm{R}_{2}$ is $\mathrm{S}$-regular fuzzy ring, there exists a prime fuzzy singleton $y_{t}=y_{t}+0 \subseteq \mathrm{R}_{1} \oplus \mathrm{R}_{2}$, such that $\mathrm{x}_{\mathrm{t}}=\mathrm{x}_{\mathrm{t}} y_{t} \mathrm{x}_{\mathrm{t}}=\left(\mathrm{r}_{\ell 1}+\mathrm{r}_{\ell 2}\right) y_{t}\left(\mathrm{r}_{\ell 1}+\mathrm{r}_{\ell 2}\right)$

$=r_{\ell 1} y_{t} r_{\ell 1}+r_{\ell 1} y_{t} r_{\ell 2}+r_{\ell 2} y_{t} r_{\ell 1}+r_{\ell 2} y_{t} r_{\ell 2}$

But $\mathrm{r}_{\ell 1} y_{t} \mathrm{r}_{\ell 2}, \mathrm{r}_{\ell 2} y_{t} \mathrm{r}_{\ell 1} \subseteq \mathrm{R}_{1} \cap \mathrm{R}_{2}$ and $\mathrm{R}_{1} \cap \mathrm{R}_{2}=(0)$

Thus $x_{t}=r_{\ell 1}+r_{\ell 2}=r_{\ell 1} y_{t} r_{\ell 1}+r_{\ell 2} y_{t} r_{\ell 2}$.

Implies that $\mathrm{r}_{\ell 1}=\mathrm{r}_{\ell 1} y_{t} \mathrm{r}_{\ell 1} \subseteq \mathrm{R}_{1}$

Therefore $R_{1}$ is S-regular fuzzy ring.

And if $0+y_{t} \subseteq \mathrm{R}_{1} \oplus \mathrm{R}_{2}$, by same method we get $\mathrm{r}_{\ell 2}=\mathrm{r}_{\ell 2} y_{t} \mathrm{r}_{\ell 2} \subseteq \mathrm{R}_{2}$

Hence $R_{2}$ is $S$-regular fuzzy ring.

\section{§3.Strongly Pure Fuzzy Submodules}

\section{$\underline{\text { Definition (3.1) }}$}

Let $\mathrm{X}$ be a fuzzy module of an R-module $\mathrm{M}$ and let $\mathrm{A}$ be a fuzzy sub modules of $\mathrm{X}$. $\mathrm{A}$ is called Strongly pure fuzzy submodule denoted by S-pure fuzzy submodule . if there exists a prime fuzzy ideal $\mathrm{P}$ of a ring $\mathrm{R}$ such that $\mathrm{PX} \cap \mathrm{A}=\mathrm{PA}$.

\section{$\underline{\text { Proposition (3.2) }}$}

let B be fuzzy submodules of a fuzzy module $X$. Then B is S-pure fuzzy submodule of $X$ if and only if $B_{t}$ is $S$-pure submodules of $X_{t}, \forall t \in(0,1]$.

Proof:

Let $\mathrm{I}$ be a prime ideal of ring $\mathrm{R}$

Define $P: R \rightarrow[0,1]$ by $P(x)=\left\{\begin{array}{cc}t & \text { if } x \in I \\ 0 & \text { otherwise }\end{array} \quad \forall t \in(0,1]\right.$

And let $\mathrm{N}$ be a submodule of an $\mathrm{R}$-module $\mathrm{M}$.

Define $\mathrm{B}: \mathrm{M} \rightarrow[0,1]$ by $\mathrm{B}(\mathrm{x})=\left\{\begin{array}{cc}\mathrm{t} & \text { if } \mathrm{x} \in \mathrm{N} \\ 0 & \text { otherwise }\end{array} \quad \forall \mathrm{t} \in(0,1] \quad\right.$ It is clear that $\mathrm{P}$ is a prime fuzzy ideal of $\mathrm{R}$ and $\mathrm{B}$ is fuzzy submodules of $\mathrm{X}$.

Now, $B_{t}=N, P_{t}=I, X_{t}=M$

$(\Longrightarrow)$ Let B is S-pure fuzzy submodule of $X$. To prove $B_{t}$ is $S$-pure submodules of $X_{t} \cdot \forall t \in(0,1]$.

To show that $P_{t} X_{t} \cap B_{t}=B_{t} P_{t}$

$$
\begin{aligned}
\mathrm{P}_{\mathrm{t}} \mathrm{X}_{\mathrm{t}} \cap \mathrm{B}_{\mathrm{t}} & =(\mathrm{PX})_{\mathrm{t}} \cap \mathrm{B}_{\mathrm{t}} & \text { by[2] } \\
& =(\mathrm{PX} \cap \mathrm{B})_{\mathrm{t}} & \text { by[6] }
\end{aligned}
$$




$\begin{array}{ll}=(P B)_{t} & \text { since } B \text { is } S \text {-pure } \\ =B_{t} P_{t} & \text { by[2] }\end{array}$

Thus $\mathrm{B}_{\mathrm{t}}$ is S-pure submodules of $\mathrm{X}_{\mathrm{t}}, \forall \mathrm{t} \in(0,1]$.

conversely Let $\mathrm{P}$ be a prime fuzzy ideal of $\mathrm{R}$ and $\mathrm{B}$ be a fuzzy submodules of $\mathrm{X}$ T.p B is S-pure fuzzy submodule of $\mathrm{X}$

$$
\begin{aligned}
& (\mathrm{PX} \cap \mathrm{B})_{\mathrm{t}}=(\mathrm{PX})_{\mathrm{t}} \cap \mathrm{B}_{\mathrm{t}} \quad \forall \mathrm{t} \in(0,1] . \quad \mathrm{By}[6] \\
& =\mathrm{P}_{\mathrm{t}} \mathrm{X}_{\mathrm{t}} \cap \mathrm{B}_{\mathrm{t}} \quad \text { by[2] }
\end{aligned}
$$

but $\mathrm{B}_{\mathrm{t}}$ is $\mathrm{S}$-pure submodules of $\mathrm{X}_{\mathrm{t}}$.

Then $P_{t} X_{t} \cap B_{t}=P_{t} B_{t}$

$$
=(\mathrm{PB})_{\mathrm{t}} \quad \text { by[2] }
$$

Hence $(P X \cap B)_{t}=(P B)_{t}$

$\mathrm{PX} \cap \mathrm{A}=\mathrm{PB}$

Therefore B is S-pure fuzzy submodule of $\mathrm{X}$.

\section{$\underline{\text { Remarks and Examples (3.3) }}$}

1- Let $\mathrm{M}=\mathrm{Z}_{6}$ as $\mathrm{Z}$-module and $\mathrm{N}=(\overline{3})$ and $\mathrm{K}=(\overline{2})$

Define $X: Z_{6} \rightarrow[0,1]$ by $X(x)=\left\{\begin{array}{lr}1 & \text { if } x \in M \\ 0 & \text { otherwise }\end{array}\right.$

Define $A: \mathrm{Z}_{6} \rightarrow[0,1]$ by $\mathrm{A}(\mathrm{x})=\left\{\begin{array}{cc}\mathrm{t} & \text { if } \mathrm{x} \in \mathrm{N} \\ \mathrm{o} & \text { otherwise }\end{array} \quad \forall \mathrm{t} \in(0,1]\right.$

Define $\mathrm{B}: \mathrm{Z}_{6} \rightarrow[0,1]$ by $\mathrm{B}(\mathrm{x})=\left\{\begin{array}{cc}\mathrm{t} & \text { if } \mathrm{x} \in \mathrm{K} \\ 0 & \text { otherwise }\end{array} \quad \forall \mathrm{t} \in(0,1]\right.$

It is clear that $\mathrm{X}$ is fuzzy module, and $\mathrm{A}, \mathrm{B}$ is fuzzy submodules of $\mathrm{X}$

$$
\mathrm{X}_{\mathrm{t}}=\mathrm{M}, \mathrm{A}_{\mathrm{t}}=\mathrm{N} \text { and } \mathrm{B}_{\mathrm{t}}=\mathrm{K}
$$

$A_{t}$ is S-pure submodules of $X_{t}$. by[5]

Then $\mathrm{A}$ is S-pure fuzzy submodule of $\mathrm{X}$ by(proposition 3.3.2)

But $\mathrm{B}_{\mathrm{t}}$ is not $\mathrm{S}$-pure fuzzy submodule of $\mathrm{Z}_{6}$

Therefore B is not S-pure fuzzy submodule of $\mathrm{X}$. by(proposition 3.3.2)

2- Let $\mathrm{X}$ be a fuzzy module of an R-module $\mathrm{M}$, and let $\mathrm{C}$ be S-pure fuzzy submodule of $\mathrm{X}$, then $\mathrm{C}$ is pure fuzzy submodule of $\mathrm{X}$. 
Proof: it is clear

The converse not true for example

Example: Let $\mathrm{M}=Z_{12}$ as $\mathrm{Z}$-module and $\mathrm{N}=(\overline{3})$

Define $X: M \rightarrow[0,1]$ by $X(x)=\left\{\begin{array}{rr}1 & \text { if } x \in M \\ 0 & \text { otherwise }\end{array}\right.$

Define $C: M \rightarrow[0,1]$ by $A(x)=\left\{\begin{array}{cc}t & \text { if } x \in N \\ 0 & \text { otherwise }\end{array} \quad \forall \mathrm{t} \in(0,1]\right.$

It is clear that $\mathrm{X}$ is fuzzy module, $\mathrm{C}$ is fuzzy submodules of $\mathrm{X}, \mathrm{X}_{\mathrm{t}}=\mathrm{M}$ and $\mathrm{C}_{\mathrm{t}}=\mathrm{N}$

$\mathrm{C}_{\mathrm{t}}$ is pure submodules of $\mathrm{X}_{\mathrm{t}}$. by[18]

Thus $\mathrm{C}$ is pure fuzzy submodule of $\mathrm{X}$ by[4]

But $C_{t}$ is not S-pure submodules of $\mathrm{X}_{\mathrm{t}}$. by [5]

Therefore $\mathrm{C}$ is not S-pure fuzzy submodule of $\mathrm{X}$. by(proposition 3.3.2)

\section{Proposition (3.4)}

let $\mathrm{A}$ be fuzzy submodules of a fuzzy module $\mathrm{X}$ and let $\mathrm{B}$ be fuzzy submodules of $\mathrm{A}$. if $\mathrm{A}$ is pure fuzzy submodule of $\mathrm{X}$ and $\mathrm{B}$ is S-pure fuzzy submodules of $\mathrm{A}$, then $\mathrm{B}$ is S-pure fuzzy submodules of $\mathrm{X}$.

Proof:

Let $\mathrm{B}$ is S-pure fuzzy submodules of $\mathrm{A}$, there exists a prime fuzzy ideal $\mathrm{P}$ of $\mathrm{R}$ such that $\mathrm{PA} \cap \mathrm{B}=\mathrm{PB}$

Since $A$ is pure fuzzy submodule of $X$, then $P X \cap A=P A$.

Implies that $\mathrm{B} \cap \mathrm{A} \cap \mathrm{XP}=\mathrm{BP}$, and since $\mathrm{B} \subseteq \mathrm{A}$, then $\mathrm{B} \cap \mathrm{A}=\mathrm{B}$

Implies $\mathrm{XP} \cap \mathrm{B}=\mathrm{PB}$

Therefore B is S-pure fuzzy submodules of $\mathrm{X}$.

\section{Corollary (3.5)}

let $\mathrm{A}$ and $\mathrm{B}$ are two fuzzy submodule of a fuzzy module $\mathrm{X}$. if $\mathrm{A}$ is pure fuzzy submodule of $\mathrm{X}$ and $\mathrm{A} \cap \mathrm{B}$ is S-pure fuzzy submodules of $\mathrm{A}$. then $\mathrm{A} \cap \mathrm{B}$ is S-pure fuzzy submodules of $\mathrm{X}$. 


\section{§4.Strongly Regular Fuzzy Module}

\section{$\underline{\text { Definition (4.1) }}$}

Let $X$ be a fuzzy module of an R-module $M$, an fuzzy $x_{t} \subseteq X, \forall t \in(0,1]$ is called strongly regular fuzzy denoted by S-regular fuzzy if there exists a fuzzy module homomorphism $\theta: M \rightarrow R$, such that $\theta\left(x_{t}\right) x_{t}=x_{t}$ where $\theta\left(x_{t}\right)$ is S-regular fuzzy singleton in a ring $R$.

\section{Definition (4.2)}

Let $X$ be a fuzzy module of an R-module $M$, is called S-regular fuzzy if every $x_{t} \subseteq X, \forall t \in(0,1]$ is S-regular fuzzy

\section{$\underline{\operatorname{Remark}(4.3)}$}

Let $\mathrm{X}$ is S-regular fuzzy modules and $\mathrm{A}$ be a prime fuzzy submodule of $\mathrm{X}$, then $\mathrm{A}$ is $\mathrm{S}$ regular fuzzy submodule of $\mathrm{X}$.

Proof:

Let $\mathrm{A}$ be a fuzzy submodule of $\mathrm{X}$ and $\mathrm{I}$ be a fuzzy ideal of $\mathrm{R}$

To show that $\mathrm{IX} \cap \mathrm{A}=\mathrm{IA}$

It is clear that $\mathrm{IA} \subseteq \mathrm{IX} \cap \mathrm{A}$

To prove IX $\cap \mathrm{A} \subseteq \mathrm{IA}$

Let $\mathrm{x}_{\mathrm{t}} \subseteq \mathrm{IX} \cap \mathrm{A}$, then $\mathrm{x}_{\mathrm{t}}=\sum_{i=1}^{n} \mathrm{r}_{\ell \mathrm{i}} \mathrm{x}_{\mathrm{ti}} \forall \mathrm{t}, \ell \in(0,1]$. Where $\mathrm{r}_{\ell \mathrm{i}} \subseteq \mathrm{I}$ and $\mathrm{x}_{\mathrm{ti}} \subseteq \mathrm{X}$

Since $\mathrm{X}$ is S-regular fuzzy R-modules , hence $\mathrm{x}_{\mathrm{t}}$ S-regular fuzzy singleton

Thus there exists a fuzzy module homomorphism $\theta: M \rightarrow R$, such that $x_{t}=\theta\left(x_{t}\right) x_{t}$, so $\theta\left(x_{t}\right)$ $=\sum_{i=1}^{n} \mathrm{r}_{\ell \mathrm{i}} \theta\left(\mathrm{x}_{\mathrm{ti}}\right)$ and $\mathrm{x}_{\mathrm{t}}=\theta\left(\mathrm{x}_{\mathrm{t}}\right) \mathrm{x}_{\mathrm{t}}=\sum_{i=1}^{n} \mathrm{r}_{\ell \mathrm{i}} \theta\left(\mathrm{x}_{\mathrm{ti}}\right) \mathrm{x}_{\mathrm{t}}$

And since $\mathrm{x}_{\mathrm{t}} \subseteq \mathrm{A}$, hence $\mathrm{x}_{\mathrm{t}}=\sum_{i=1}^{n} \mathrm{r}_{\ell \mathrm{i}} \theta\left(\mathrm{x}_{\mathrm{ti}}\right) \mathrm{x}_{\mathrm{t}} \subseteq \mathrm{IA}$

Thus IX $\cap \mathrm{A} \subseteq \mathrm{IA}$

Then IX $\cap A=I A$

Therefore A is S-regular fuzzy submodule of $\mathrm{X}$.

\section{Proposition (4.4)}

Let $\mathrm{R}$ be a S-regular fuzzy ring $\Leftrightarrow \mathrm{R}$ is S-regular fuzzy $\mathrm{R}$-module.

Proof:

Let $\mathrm{R}$ be a S-regular fuzzy ring to prove $\mathrm{R}$ is $\mathrm{S}$-regular fuzzy $\mathrm{R}$-module. 
Let $\mathrm{x}_{\mathrm{t}} \subseteq \mathrm{R}$, thus there exists a prime fuzzy singleton $\mathrm{p}_{\mathrm{s}} \subseteq \mathrm{R}$ such that $\mathrm{x}_{\mathrm{t}}=\mathrm{x}_{\mathrm{t}} \mathrm{p}_{\mathrm{s}} \mathrm{x}_{\mathrm{t}}, \forall \mathrm{t}, \ell \in(0,1]$.

Now, define a function $\theta: R \rightarrow R$, by $\theta\left(x_{t}\right)=x_{t} p_{s}$ for each fuzzy singleton $x_{t}$ of $R$

Then $\theta\left(x_{t}\right) x_{t}=x_{t} p_{s} x_{t}$, so $\theta\left(x_{t}\right) x_{t}=x_{t}$

Thus $\mathrm{R}$ is S-regular fuzzy R-module.

Conversely let $\mathrm{R}$ is S-regular fuzzy $\mathrm{R}$-module to prove $\mathrm{R}$ is $\mathrm{S}$-regular fuzzy ring .

Let $x_{t} \subseteq R$, there exists a fuzzy module homomorphism $\theta: R \rightarrow R$, such that $x_{t}=\theta\left(x_{t}\right) x_{t}$, where $\theta\left(x_{t}\right)$ is S-regular fuzzy singleton of $\mathrm{R}$.

Since $\theta\left(x_{t}\right)=\theta\left(1 \cdot x_{t}\right)=\theta(1) x_{t}$,

Hence $x_{t} p_{s} x_{t}=x_{t} \theta(1) x_{t}$

Therefore $\mathrm{R}$ is S-regular fuzzy ring .

\section{Proposition (4.5)}

Let $\mathrm{X}$ is S-regular fuzzy module and fuzzy divisible over an fuzzy integral domain $\mathrm{R}$, then every fuzzy submodule of $\mathrm{X}$ is fuzzy divisible.

\section{Proof:}

Let $A$ be a fuzzy submodule of $X$, and $0 \neq r_{\ell} \subseteq R$

We show that $r_{\ell} A=A$

By remark(3.4.3) A is S-pure fuzzy submodules of $\mathrm{X}$.

so $<\mathrm{r}_{\ell}>A=A \cap<\mathrm{r}_{\ell}>\mathrm{X}$

We show that $r_{\ell} A=A \cap r_{\ell} X$, if $x_{t} \subseteq A \cap r_{\ell} X$, then $x_{t}=r_{\ell} s_{r}$

Since $x_{t}$ is S-regular fuzzy of $X$ there exists a fuzzy module homomorphism $\theta: M \rightarrow R$, such that $\mathrm{x}_{\mathrm{t}}=\theta\left(\mathrm{x}_{\mathrm{t}}\right) \mathrm{x}_{\mathrm{t}}$ and hence $\mathrm{x}_{\mathrm{t}}=\theta\left(\mathrm{x}_{\mathrm{t}}\right) \mathrm{x}_{\mathrm{t}}=\mathrm{r}_{\ell} \theta\left(\mathrm{s}_{\mathrm{r}}\right) \mathrm{x}_{\mathrm{t}}$, as $\mathrm{x}_{\mathrm{t}} \subseteq \mathrm{A}$

This implies that $\mathrm{x}_{\mathrm{t}} \subseteq \mathrm{r}_{\ell} \mathrm{A}$, hence $\mathrm{A} \cap \mathrm{r}_{\ell} \mathrm{X} \subseteq \mathrm{r}_{\ell} \mathrm{A}$,

Hence $r_{\ell} A=A \cap r_{\ell} X$.

As $r_{\ell} X=X$. thus $A \cap X=r_{\ell} A$

So $r_{\ell} A=A$

Therefore A is fuzzy divisible. 


\section{Proposition (4.6)}

Let $\mathrm{X}$ be a S-regular fuzzy $\mathrm{R}$-module $\mathrm{M}$, then $\mathrm{F}-\mathrm{J}(\mathrm{R}) \mathrm{X}=0$

Proof:

Since $\mathrm{X}$ is S-regular fuzzy R-module,

Thus every fuzzy submodules of $\mathrm{X}$ is S-pure fuzzy submodules by remark(3.4.3)

Let F-J $(\mathrm{R}) \mathrm{X} \neq 0$, therefore there exists $\mathrm{x}_{\mathrm{t}} \subseteq \mathrm{F}-\mathrm{J}(\mathrm{R})$

So $\mathrm{Rx}_{\mathrm{t}}$ is S-pure fuzzy submodules of $\mathrm{X}$

Thus $\mathrm{Rx}_{\mathrm{t}} \cap \mathrm{F}-\mathrm{J}(\mathrm{R}) \mathrm{X}=\mathrm{F}-\mathrm{J}(\mathrm{R}) \mathrm{Rx}_{\mathrm{t}}$

Then $\mathrm{Rx}_{\mathrm{t}}=\mathrm{F}-\mathrm{J}(\mathrm{R}) \mathrm{Rx_{ \textrm {t } }}$ and by lemma(3.4.6) $\mathrm{Rx} \mathrm{x}_{\mathrm{t}}=0$ so $\mathrm{x}_{\mathrm{t}}=0$

Hence F-J(R) X=0

\section{REFERENCES}

1-Inaam M-A.H, 'On Fuzzy Ideals of Fuzzy Rings', Math. And Physics, Vol. 16, PP.4, (2001).

2-Kumar, R., S.k. Bhambir, Kumar, p.," Fuzzy Submodules, Some Analogous and Deviation”, Fuzzy Sets and Systems, 70,125-130,(1995).

3-Malik, D. S. and Mordeson, J.N., "Fuzzy Maximal, Radical and Primary Ideals of a Ring", Information Sciences, Vol.53,237-250,(1991).

4-Maysoun A. H., 'F-Regular Fuzzy Modules", M. Sc. Thesis , University of Baghdad,(2002).

5-Nada K. A.," Strongly Pure Ideals And Strongly Pure Submodules", Kirkuk University Journal ,Vol.10, Issue 1, PP. 12-28, (2015).

6-Zadeh L. A., "Fuzzy Sets, Information and Control", ,Vol. 8,PP.338-353,(1965). 